
20

\title{
Light-Induced Crystallization-Driven Formation of Hierarchically Ordered Superhydrophobic Sol-Gel Coatings
}

Lingli Ni, ${ }^{\dagger} *$ Cheng Zhu, ${ }^{\dagger}$ Shizhong Zhang, ${ }^{\dagger}$ Peng Cai, ${ }^{\dagger} * *$ Aissam Airoudj, ${ }^{\dagger, 8}$ Laurent Vonna, ${ }^{\ddagger}, \S$

Samar Hajjar-Garreau, ${ }^{\ddagger}$, and Abraham Chemtob ${ }^{\ddagger},, *$

${ }^{\dagger}$ Key Laboratory for Palygorskite Science and Applied Technology of Jiangsu Province, College of Chemical Engineering, Huaiyin Institute of Technology, 223003 Huaian, People's Republic of China

*Université de Haute-Alsace, CNRS, IS2M UMR7361, F-68100 Mulhouse, France

${ }^{\S}$ Université de Strasbourg, France

\section{*Corresponding authors:}

Dr. Lingli Ni; E-mail: linglini@hyit.edu.cn; Tel: +86 5178355 9056; Fax: +86 5178355 9056

Dr. Peng Cai; E-mail: caipeng16@ @yit.edu.cn; Tel: +86 5178355 9619; Fax: +86 5178355 9056;

Dr. Abraham Chemtob; E-mail: abraham.chemtob@uha.fr; Tel: +33 38960 8799; Fax: +33 3 89335017 ; 


\section{Abstract}

Nano/micro structures are crucial for superhydrophobic surfaces, but rare are methods able to generate such dual structuring in a single step using a single precursor. We show that the visible light-controlled self-assembly of bis-silylated alkane precursors can create in one-step organosilica coatings exhibiting two levels of hierarchy: lamellae at nanoscale, and plate-like crystals at microscale. Crystallization rate can be precisely controlled by alkylene bridging group and irradiance. This allowed us to achieve superhydrophobic properties by the creation of a dense and uniform network of nanostructured microcrystals with high surface roughness. The obtained coatings displayed chemical stability, good thermal resistance and high mechanical strength through the cross-linked siloxane structure, which is essential for applications.

Keywords: superhydrophobic; silsesquioxane; photo sol-gel; crystallization

\section{Introduction}

Superhydrophobic surfaces combining water contact angles higher than $150^{\circ}$ and low contact angle hysteresis have attracted extensive interest from both an economic and an academic perspective [1-3]. High water repellency properties can ensure further developments in many advanced materials with broad potential application $[1,4]$, such as self-cleaning surfaces [5-7], anti-corrosive coatings [8-11], drag reduction [12-14], or microfluidic devices [15]. It is now well established that a combination of low-surface-energy material and hierarchical micro/nanoscopic structure is a key feature to fabricate superhydrophobic surfaces $[16,17]$. 
Inspired by lotus leaf [18], many different approaches have been developed to achieve both properties in a single coating. Lithography [19], plasma or chemical etching [20], controlled crystallization [21, 22], phase separation phenomena [23], electrochemical deposition [24], chemical vapor deposition [25], and self-assembly [26-28] are the main ones. Despite the diversity of synthetic methodologies, there are still many obstacles to a widespread use of superhydrophobic materials, including multiple steps, use of aggressive chemical reagents, or complex instrumentations [29]. In this context, a facile, cost-effective and environmentally friendly method to superhydrophobic coatings would be highly desirable [6].

In response to this major challenge, we report herein a superhydrophobic sol-gel coating produced in a single-step from a single precursor. As depicted in Figure 1, the photoinduced condensation of a $\alpha, \omega$-bis-silylated alkane was able to create a superhydrophobic hierarchical structure driven by the self-assembly of the organosilica network. Conventional sol-gel process based on specific organosilane [30-33] or polyhedral oligomeric silsesquioxane [34, 35] precursors have long been recognized as a major method for the preparation of superhydrophobic coatings. By contrast, the development of a radiation-mediated sol-gel process has received little attention so far. This in spite of the fact that photopolymerization is considered today as one of the most eco-efficient organic coating technologies [36]. The few studies reporting a light-driven route to superhydrophobic coatings involved volatile organic solvents either to ensure deposition [37, 38] or to induce roughness by phase separation [39] or simple evaporation [40]. In addition, their green credentials were undermined by the use of ultraviolet (UV) radiation and perfluorinated chemicals, both having potential health effects. By contrast, our methodology is based on a solvent-free sol-gel photopolymerization of 
1,6-bis(trimethoxysilyl)hexane $\left(\left(\mathrm{H}_{3} \mathrm{CO}\right)_{3} \mathrm{Si}-\left(\mathrm{CH}_{2}\right)_{6}-\mathrm{Si}\left(\mathrm{OCH}_{3}\right)_{3}, \quad \mathrm{BC}_{6} \mathrm{TMS}\right)$ performed at ambient temperature, low irradiance $\left(<1 \mathrm{~mW} \mathrm{~cm}^{-2}\right)$ and using a $405 \mathrm{~nm}$ light-emitting diode (LED). A visible radiation promotes a safer environment, while the use of LEDs offer many technical advantages compared to conventional mercury arcs [41]. While alkoxysilane sol-gel photopolymerization is already a well established approach to design nanostructured organosilica coatings $[42,43]$, it has been harnessed as a way to create a hierarchically ordered micro/nanostructure which is ideal for achieving superhydrophobicity. By precise energetic dosage of irradiation, crystallization conditions can be finely tuned to yield in a single-step a silsesquioxane coating $\left((\mathrm{OH})_{3-\mathrm{x}} \mathrm{O}_{\mathrm{x}} \mathrm{Si}-\left(\mathrm{CH}_{2}\right)_{6}-\mathrm{SiO}_{\mathrm{x}}(\mathrm{OH})_{3-\mathrm{x}}, \mathrm{BC}_{6} \mathrm{SQ}\right)$ composed of crystalline nanolayers assembling in microcrystals with high surface roughness. In this work, the conditions to create a superhydrophobic surface from such hierarchically ordered structure have been investigated. The challenge lies in the capacity to control template-free organosilane self-assembly, microcrystals growth and surface energy of the hybrid coating.

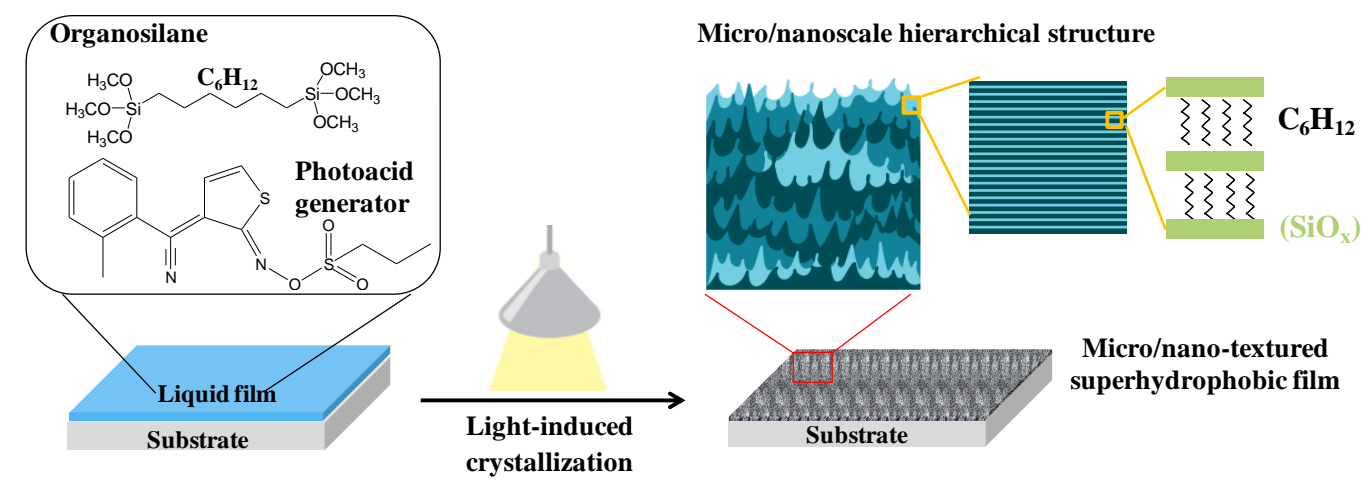

Figure 1. Schematic illustration showing the visible light-induced crystallization process of a bis-silylated alkane precursor forming a micro/nano structured organosilicate coating. 


\section{Experimental section}

\section{Chemicals}

$$
\text { 1,2-Bis(trimethoxysilyl)ethane (95\%) and 1,6-bis(trimethoxysilyl)hexane (95\%) were }
$$
supplied by Gelest. Trimethylsiloxy teminated poly(dimethyl siloxane) (PDMS, $3.0 \mathrm{cSt}, 550$ g/mol) was purchased from Fluochem. Trimethoxysilane and 1,9-decadiene were purchased from Aladdin and TCI chemicals (Shanghai), respectively. Photoacid generator Irgacure PAG103 was provided by BASF. All of the chemicals were used as received.

\section{Synthesis of 1,10-bis(trimethoxysilyl)decane}

1,10-Bis(trimethoxysilyl)decane was prepared according to the previous literature procedure [44]. Typically, $6.9 \mathrm{~g}$ of 1,9 -decadiene $(0.05 \mathrm{~mol}), 12.3 \mathrm{~g}$ of trimethoxysilane $(0.1 \mathrm{~mol})$ and 0.35 $\mathrm{ml}$ of chloroplatinic acid in isopropanol $\left(2.73 \times 10^{-3} \mathrm{M}\right)$ were mixed together by magnetic stirring, then the mixture was heated to $100{ }^{\circ} \mathrm{C}$ and refluxed for 6 hours under nitrogen atmosphere. After distillation of the reaction mixture under vacuum, $6.7 \mathrm{~g}$ (35\% yield) of 1,10-bis(trimethoxysilyl)decane was collected. ${ }^{1} \mathrm{H}$ NMR (400 MHz, $\left.\mathrm{CDCl}_{3}\right): \delta(\mathrm{ppm}) 0.58(\mathrm{t}, 4$ $\mathrm{H}), 1.17-1.6(\mathrm{~m}, 34 \mathrm{H}), 3.7$ (q, $12 \mathrm{H}) ;{ }^{13} \mathrm{C}$ NMR (100 MHz, $\left.\mathrm{CDCl}_{3}\right): \delta(\mathrm{ppm}) 10.3,18.3,22.7$, $29.2,29.5,33.2,58.2$.

\section{Preparation of hierarchically ordered coating}

In a typical procedure, photoacid generator (PAG103, $0.5 \% \mathrm{wt}$.) was dissolved in a mixture of 1,6-bis(trimethoxysilyl)hexane and PDMS (75/25 wt. \%) to form a photolatent solution in the absence of light. Then the resultant formulation was deposited on a silicon wafer or glass substrate by spin coating (1000 rpm, $20 \mathrm{~s}$ ) to produce a liquid coating. UV-curing was performed at room temperature under the light of a LED lamp (Shenzhen xianghe, $20 \mathrm{~W}$ ) with 
a controlled irradiance from 20 to $0.1 \mathrm{~mW} \mathrm{~cm}^{-2}$. The samples were irradiated $1800 \mathrm{~s}$ to yield solid silsesquioxane hybrid coatings $(\sim 4 \mu \mathrm{m})$. During irradiation, the relative humidity $(\mathrm{RH})$ was maintained between 50 and $55 \%$.

\section{Characterization}

Infrared spectra were recorded with a spectrophotometer equipped with a MCT detector. The resolution of the infrared spectra was $2 \mathrm{~cm}^{-1}$. X-ray diffraction patterns (XRD) were obtained on a Bruker D8-Discover diffractometer with fixed slits using $\mathrm{Cu} / \mathrm{K} \alpha$ radiation $(\lambda=1.5418 \AA)$ and $\theta-2 \theta$ mounting. Before analysis, coatings on silicon wafers were directly deposed on a plastic sample holder. Data were collected between 1 and $30^{\circ} 2 \theta$ degrees (XRD) with a scanning step of $0.01^{\circ} \mathrm{s}^{-1}$. Morphologies of the samples were characterized by scanning electron microscopy (SEM, Hitachi S3000N microscope working at $30 \mathrm{kV}$ ). The samples being non-conductive, they were metalized with gold (15 nm thickness). Water contact angles were measured by sessile drop experiments on a DSA25 contact angle goniometer (Krüss GmbH, Germany) with $6 \mu \mathrm{L}$ deionized water droplet. Atomic Force Microscopy (AFM) measurements were carried out in a Bruker Multimode IV, with a Nanoscope V controller and an E "vertical" scanner, by the Peak Force Quantitative Nanomechanical Mapping (PF-QNM, Bruker) method. PF-QNM is a contact AFM mode, based on the force-volume method. In this method, force distance curves are collected by nanoindentation of the sample in a point-by-point mode. During measurement, the maximum (peak force) is controlled at each pixel to obtain force-distance curves which are then used as feedback signal. In this method, the loading and unloading force-distance curves are collected at a frequency of $2 \mathrm{kHz}$ at each position within the mapped area of the specimen. In parallel to topography images, information on material 
elasticity (Young's modulus), tip-to-surface adhesion were obtained. All the experiments were carried out in air and at room temperature. $5 \mu \mathrm{m} \times 5 \mu \mathrm{m}(256 \times 256$ pixels at $0.5 \mathrm{~Hz})$ were taken at three different areas on the sample surface. To get relevant results, the cantilever and the tip geometry are taking into account in the PF-QNM measurements. Thus, a calibration procedure was first followed. All quantitative measurements were carried out with RTESPA-300 cantilever (Bruker, USA) with a spring constant of $40 \mathrm{~N} \mathrm{~m}^{-1}$ and resonance frequency of 300 $\mathrm{kHz}$, a width of $40 \mu \mathrm{m}$ and a length of $125 \mu \mathrm{m}$. Thanks to the Sader method [45] (using the length, the width, the resonance frequency and the quality factor of the cantilever) the actual spring constant was determined and found to be around $42 \mathrm{~N} \mathrm{~m}^{-1}$. Then, the deflection sensitivity (around $33 \mathrm{~nm} \mathrm{~V}^{-1}$ ) was measured on a sapphire surface. Tip radius was calibrated against a polystyrene standard provided by Bruker. The measured value of the tip radius was 30 nm. The Poisson's ratio was assumed to be equal to 0.3 . For all experiments, samples were previously (at least half a day before) fixed on a sample holder with a double-sided tape. X-ray photoelectron spectroscopy (XPS) analyses were performed with a VG Scienta SES 2002 spectrometer equipped with a monochromatized $\mathrm{Al}(\mathrm{K} \alpha) \mathrm{X}$-ray source $(1486.6 \mathrm{eV})$, a hemispherical analyzer and an electron gun to compensate the charging effect. The high resolution spectra and wide scan were recorded with pass energy of $100 \mathrm{eV}$ and $500 \mathrm{eV}$ respectively. The analyzed zone had a surface of $24 \mathrm{~mm}^{2}$. The decomposition of the spectra into different components was performed with Gaussian-Lorentzian, after having subtracted a Shirley-type background. The mean composition of the sample surface expressed in atomic percentages was determined using integrated peak areas of each component, and taking into account the transmission factor of the spectrometer, means free path, and sensibility factors of 
each atom. The bouncing of the droplets was recorded with a high-speed camera (4M180-CL from IO Industries Inc., London, ON, Canada) at a frame rate of $500 \mathrm{fps}$. The impact velocities were calculated from the five last images before the contact between the droplet and the surface.

We used a microsyringe with a tip geometry allowing to deliver water droplets with a diameter of $2.7 \mathrm{~mm} \pm 0.2 \mathrm{~mm}$. The height of the syringe tip was increased in order to reach high impact velocities. With these droplet diameters, the highest impact velocities considered in this work were around than $1.2 \mathrm{~m} / \mathrm{s}^{-1} \pm 0.1 \mathrm{~m} \cdot \mathrm{s}^{-1}$. Beyond these velocities, fragmentation of the droplets was observed. As for the sessile drop experiments, we used fresh deionized water. The abrasion resistance of the superhydrophobic surface was evaluated by a homemade Taber abrasion equipment. The test specimen was placed on the abrasion tester. A $100 \mathrm{~g}$ load was then placed on top of the abrader wheel (1500-mesh sandpaper) and allowed to spin for a specified number of revolutions at a speed of $3 \mathrm{~cm} \cdot \mathrm{s}^{-1}$. The contact area between the abrader wheel and the underlying superhydrophobic coating was $4.8 \mathrm{~cm}^{2}$. Water CA and sliding angle of test specimen were measured after different number of abrasion cycles.

\section{Results and discussion}

The synthesis of bridged silsesquioxane coating $\mathrm{BC}_{6} \mathrm{SQ}$ proceeds through an acid-catalyzed sol-gel photopolymerization in presence of a commercial photoacid generator (PAG, (5-propylsulfonyl-oxyimino-5H-thio-phen-2-ylidene)-(2-methylphenyl) acetonitrile). Upon exposure to visible light, $n$-propyl sulfonic acid is liberated, acting as a catalyst for hydrolyzing methoxysilyl $\left(\mathrm{Si}_{-}-\mathrm{OCH}_{3}\right)$ functions into $\mathrm{Si}-\mathrm{OH}$, and for their subsequent condensation into siloxane ( $\mathrm{Si}-\mathrm{O}-\mathrm{Si})$ bonds. This series of reactions was triggered by 
171 irradiating a $\mathrm{BC}_{6} \mathrm{TMS} / \mathrm{PAG}$ coating $(1 / 0.005 \mathrm{wt} \%$, thickness: $4 \mu \mathrm{m})$ with a $405 \mathrm{~nm}$ LED lamp at

172 low irradiance $\left(0.5 \mathrm{~mW} \mathrm{~cm}{ }^{-2}\right)$ during $30 \mathrm{~min}$. The efficiency of the photo sol-gel process was

173 supported by FTIR spectroscopy (Figure 2) through the disappearance of the $\mathrm{CH}_{3}$ symmetric

174 stretch of $\mathrm{SiO}-\mathrm{CH}_{3}$ groups at $2840 \mathrm{~cm}^{-1}$ and the concomitant emergence of a broad band at

$1753000-3400 \mathrm{~cm}^{-1}$, indicative of the silanol formation. The presence of asymmetric stretching

176 bands of siloxane bonds at 1100 and $1070 \mathrm{~cm}^{-1}$ proved the formation of the

177 polysilsesquioxane network. It was further evidenced by ${ }^{29} \mathrm{Si}$ SPE-MAS NMR spectroscopy

178 (see spectrum in Figure $\mathrm{S} 1$ in supporting information) which revealed $\mathrm{T}^{1}$ (-49 ppm,

$\left.179 \mathrm{C}-\mathrm{Si}(\mathrm{OR})_{2}(\mathrm{O}-\mathrm{Si}), 15.9 \%\right), \mathrm{T}^{2}\left(-58 \mathrm{ppm}, \mathrm{C}-\mathrm{Si}(\mathrm{OR})(\mathrm{O}-\mathrm{Si})_{2}, 59.4 \%\right)$ and $\mathrm{T}^{3}(-68 \mathrm{ppm}$,

$\left.180 \quad \mathrm{C}-\mathrm{Si}(\mathrm{O}-\mathrm{Si})_{3}, 24.7 \%\right)$ siloxane species.

181

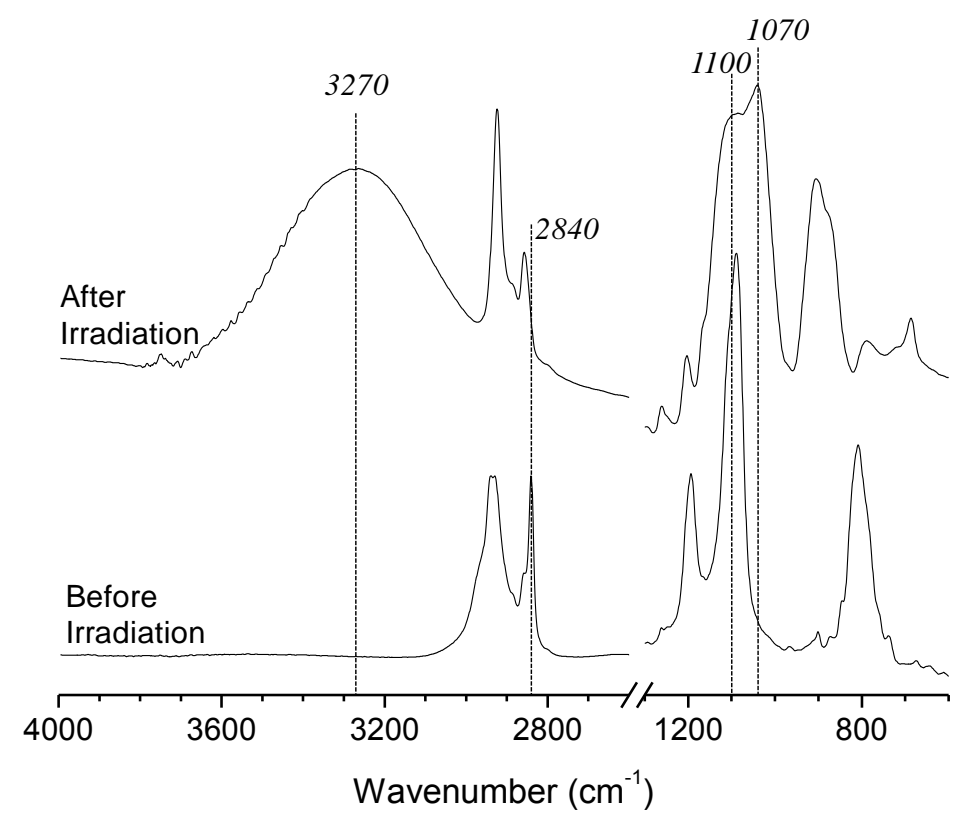

Figure 2. FTIR spectra of $\mathrm{BC}_{6} \mathrm{TMS}$-derived coating before and after the sol-gel photopolymerization $\left(\mathrm{I}=0.5 \mathrm{~mW} \mathrm{~cm}{ }^{-2}, \mathrm{RH}=50 \%, \mathrm{~T}=25^{\circ} \mathrm{C}\right)$. 
microstructuration. Figure 3 displays a representative image for $\mathrm{BC}_{6} \mathrm{SQ}$ as well as two other images obtained with bridged precursors exhibiting other chain lengths $\left(\left(\mathrm{CH}_{3} \mathrm{O}\right)_{3} \mathrm{SiC}_{\mathrm{n}} \mathrm{H}_{2 \mathrm{n}} \mathrm{Si}\left(\mathrm{OCH}_{3}\right)_{3}, \mathrm{n}=2\right.$ and 10$) . \mathrm{BC}_{2} \mathrm{SQ}$ (Figure 3a) containing the shortest bridging group formed a surface locally uneven and rough, resulting only in a moderate water contact angle $(\mathrm{CA})$ of $78.0^{\circ} \pm 0.9^{\circ}$. Upon increasing the chain length, $\mathrm{BC}_{6} \mathrm{SQ}$ (Figure 3b) revealed a uniform, highly rough surface, driving a much higher CA $\left(129.5^{\circ} \pm 1.1^{\circ}\right)$. In contrast, $\mathrm{BC}_{10} \mathrm{SQ}$ (Figure 3c) exhibited only local features protruding from the plane, leading to a sharp decrease of $\mathrm{CA}\left(85.5^{\circ} \pm 0.9^{\circ}\right)$. Further investigation of the hybrid coatings' nanostructure was performed by X-ray diffraction (XRD). As shown in Figure 3d, the coating derived from the ethylene precursor (trace a) was mainly amorphous. In contrast, increasing the alkylene chain length to $\mathrm{C}_{6}$ (trace $\mathbf{b}$ ) led to a single sharp diffraction signal, indicative of a long range ordered sample. The onset of a highly ordered nanostructure was even more evident with the $\mathrm{BC}_{10} \mathrm{SQ}$ coating whose XRD pattern (trace c) displayed 5 reflection peaks from (001) to (005) suggestive of a lamellar mesostructure. In the latter two cases, the (001) peaks at $12.3 \AA$ (b) and $16.2 \AA$ (c) were consistent with an interlamellar distance for structures based on alternating stacks of $\mathrm{C}_{\mathrm{n}} \mathrm{H}_{2 \mathrm{n}}$ bridging groups connected to a single siloxy chain. As expected in organosilane self-assembly, a higher ordering is driven by longer alkylene bridging groups because of stronger Van der Waals interactions [46]. 

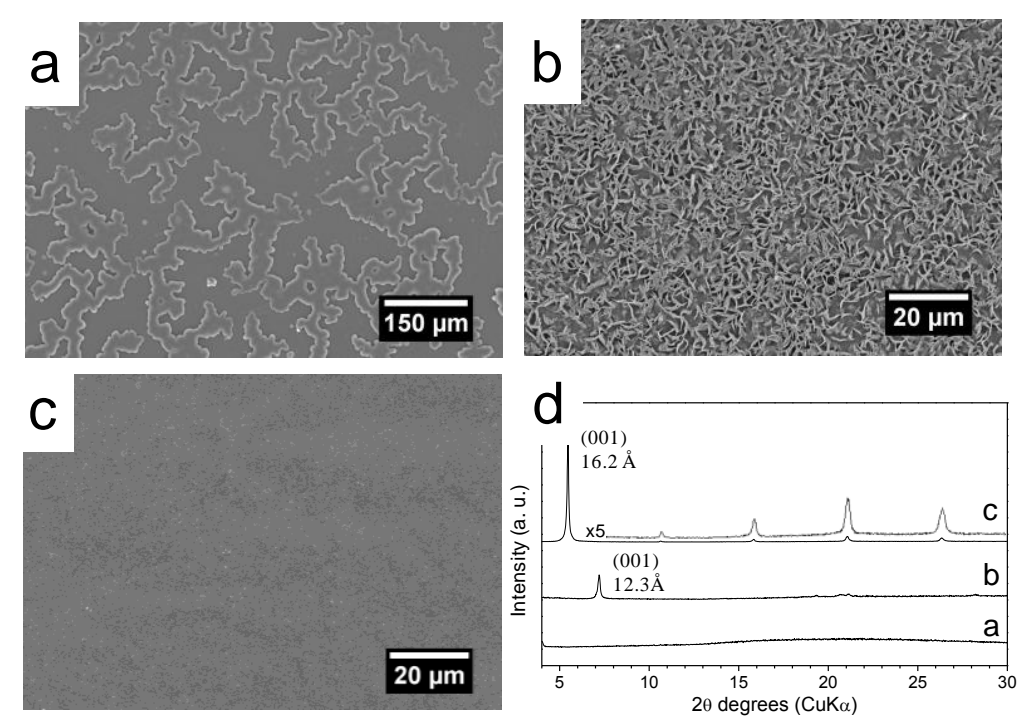

Figure 3. $\mathrm{SEM}$ micrographs of $\mathrm{BC}_{\mathrm{n}} \mathrm{SQ}$ samples derived from $\mathrm{BC}_{\mathrm{n}} \mathrm{TMS}$ precursors $\left[\left(\mathrm{CH}_{3} \mathrm{O}\right)_{3} \mathrm{SiC}_{\mathrm{n}} \mathrm{H}_{2 \mathrm{n}} \mathrm{Si}\left(\mathrm{OCH}_{3}\right)_{3}, \quad \mathrm{n}=2\right.$ (a), 6 (b), 10 (c) $]$. XRD patterns of the three photopolymerized $\mathrm{BC}_{\mathrm{n}} \mathrm{SQ}$ hybrid coatings $(\mathbf{d}) . \mathrm{I}=0.5 \mathrm{~mW} \mathrm{~cm}^{-2}, 30 \mathrm{~min}$ irradiation.

211 by the assembly of dense and regular arrays of nanolamellae. This assumption is supported by images of polarized optical microscopy confirming that the three samples (Figure S2) exhibit birefringence (anisotropy of refraction) that is characteristic of their crystalline structure. Although the microcrystals stem from the growth of lamellar nanocrystals, their density and uniformity were strongly dependent on the chain length. Compared to other precursors, $\mathrm{BC}_{6} \mathrm{SQ}$ was unique for its ability to form a homogeneous hierarchical surface through a crystallization process expressing at both nano- and microscale levels. Consequently, in the view to provide superhydrophobic properties, $\mathrm{C}_{6} \mathrm{TMS}$ was preferentially used in the rest of this study. Next efforts were focused on utilization of light, in particular irradiance, to precisely control the morphology of the $\mathrm{BC}_{6} \mathrm{SQ}$ surface. The objective was to optimize 

uniform and highly rough spiky surface.
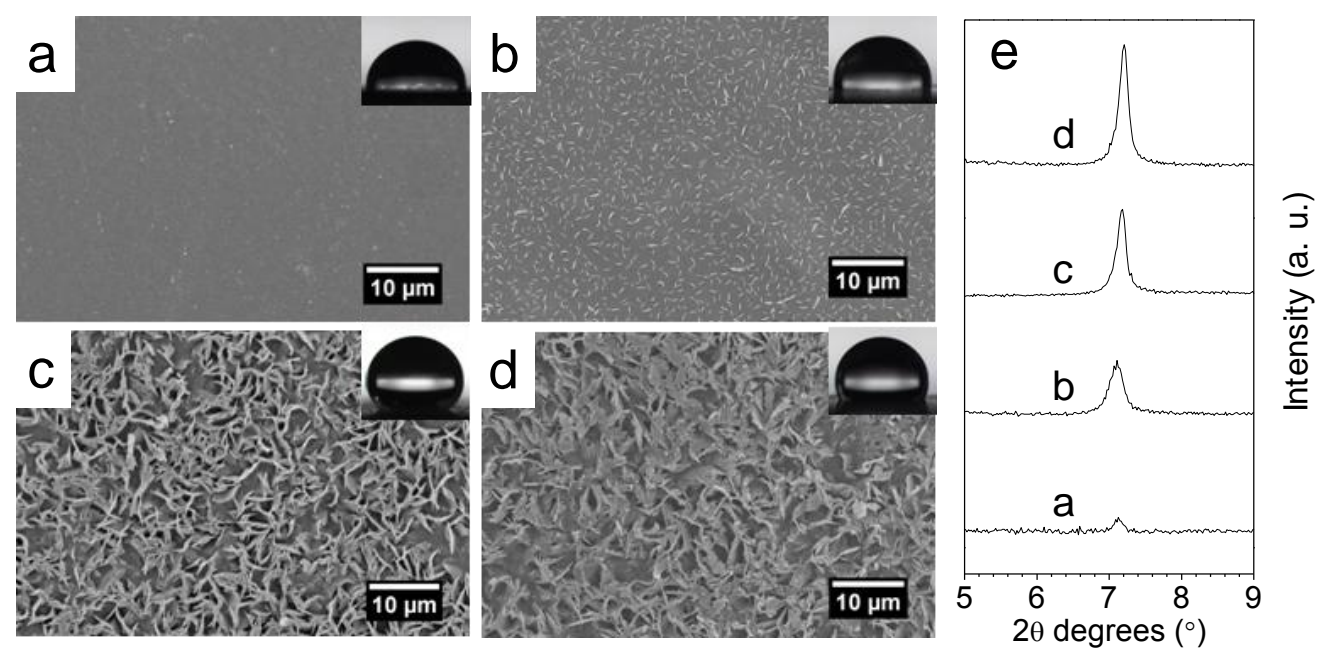

Figure 4. SEM micrographs of $\mathrm{BC}_{6} \mathrm{SQ}$ prepared at different irradiances: 20 (a), 2 (b), 0.5 (c),

0.1 (d) (unit: $\mathrm{mW} \mathrm{cm} \mathrm{cm}^{-2}, 30 \mathrm{~min}$ irradiation). The corresponding (001) XRD peak of each sample is shown on the right side (e).

Both nano- and microstructures are expected to be influenced by the crystallization time,

which is dependent on the condensation rate [47-48]. One key advantage of a radiation-mediated process is that a modulation of irradiance represents an efficient means to control this condensation kinetics. Figure 4a-d show SEM images of $\mathrm{BC}_{6} \mathrm{SQ}$ prepared at different irradiances $\left(0.1-20 \mathrm{~mW} \mathrm{~cm}^{-2}\right)$. A smooth surface with limited hydrophobic properties was obtained (Figure 4a, $\mathrm{CA}=82.0^{\circ} \pm 0.7^{\circ}$ ) at $20 \mathrm{~mW} \mathrm{~cm}{ }^{-2}$. In accordance with this result, the corresponding XRD pattern (Figure 4e) featured only a low intense (001) peak because condensation reactions were presumably too fast to favor self-assembly. Upon decreasing irradiance to $2 \mathrm{~mW} \mathrm{~cm}{ }^{-2}$, microcrystals appeared at the coating surface, resulting in an increased hydrophobicity (Figure $4 \mathbf{b}, \mathrm{CA}=95.0^{\circ} \pm 0.9^{\circ}$ ). Consistently, there was a 
sharpening and intensity increase of the (001) reflections, suggesting a higher level of ordering (Figure 4e). At $0.5 \mathrm{~mW} \mathrm{~cm}^{-2}$, the level of ordering still increased, which translated in sharper reflection peaks. Concomitantly, the size and number of flat and edgy plates on the coating surface increased, resulting in a larger $\mathrm{CA}$ value (Figure $4 \mathbf{c}, \mathrm{CA}=129.5^{\circ} \pm 1.1^{\circ}$ ). At $0.1 \mathrm{~mW} \mathrm{~cm}^{-2}$, the XRD pattern followed the same trend, but the water contact angle fell markedly (Figure $4 \mathbf{d}, \mathrm{CA}=112.0^{\circ} \pm 1.2^{\circ}$ ), likely as a result of the collapse of the poorly condensed microstructure. Therefore, an irradiance $0.5 \mathrm{~mW} \mathrm{~cm}^{-2}$ (Figure 4c) seemed the best trade-off. Under these conditions, crystallization time was slow enough to drive a high level of organization, which proved to be beneficial for a higher crystallinity and the emergence of well-defined nano- and micro-structures. Slow condensation is assumed to increase the nucleation rate and the density of flakes at the surface contributing to increase roughness. In these conditions, the inhomogeneity and size of the pores increase, contributing to the increase of water CA. Nevertheless, the present system was not yet able to achieve

251 superhydrophic properties. One possible reason is a too high surface energy of the bridged 252 silsesquioxane structure.
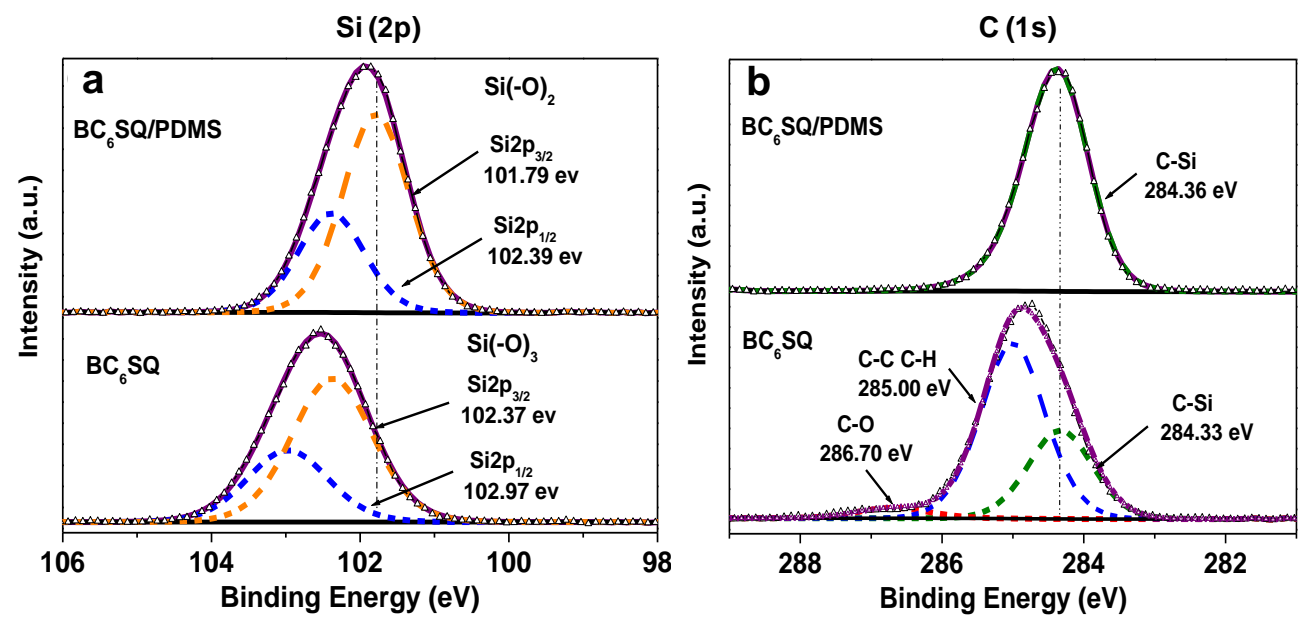

254 Figure 5. Si (2p) (a) and C (1s) (b) core level XPS spectra of $\mathrm{BC}_{6} \mathrm{SQ}$ and $\mathrm{BC}_{6} \mathrm{SQ} / \mathrm{PDMS}$. 
In order to increase the water CA, a small amount of trimethylsilyl terminated poly(dimethylsiloxane) (PDMS, $550 \mathrm{~g} / \mathrm{mol}$ ) was added. The goal was to coat the $\mathrm{BC}_{6} \mathrm{PSQ}$ microstructure with a material having a lower surface energy than alkyl bridged silsesquioxane while keeping the advantage of a one-step procedure. The analysis of the XRD pattern confirmed that this additive did not significantly alter the nanoscale organization (Figure S3), with only a slight broadening of the XRD signal. In order to assess the surface of $\mathrm{BC}_{6} \mathrm{SQ} / \mathrm{PDMS}$ was deconvoluted only in a single peak centered at $284.36 \mathrm{eV}$ assigned to migration ability of PDMS chains, X-ray photoelectron spectroscopy (XPS) was performed with $\mathrm{BC}_{6} \mathrm{SQ} / \mathrm{PDMS}$ and pure $\mathrm{BC}_{6} \mathrm{SQ}$ (Figure 5). In both cases, the Si2p peak (Figure 5a) displayed two components, $\mathrm{Si} 2 \mathrm{p}_{3 / 2}$ and $\mathrm{Si} 2 \mathrm{p}_{1 / 2}$ with a spin-orbit coupling of $0.6 \mathrm{eV}$. However, the position of these two features was distinct depending on the sample, suggesting a different Si environment. As expected, the binding energies in $\mathrm{BC}_{6} \mathrm{SQ}(102.37 \mathrm{eV}, 102.97 \mathrm{eV})$ were in agreement with the presence of $\mathrm{T}$ siloxane species $\mathrm{RSi}(\mathrm{OH})_{\mathrm{x}}(\mathrm{OSi})_{3-\mathrm{x}}$ [49]. By contrast, the positions in $\mathrm{BC}_{6} \mathrm{SQ} / \mathrm{PDMS},(101.79 \mathrm{eV}, 102.39 \mathrm{eV})$ were consistent with a majority of $\mathrm{D}$ siloxane units $\mathrm{R}_{2} \mathrm{Si}(\mathrm{OSi})_{2}$ [49] and correspond well to literature values for PDMS [50]. As shown in Figure $\mathbf{5 b}$, the $\mathrm{C} 1 \mathrm{~s}$ peak of pure $\mathrm{BC}_{6} \mathrm{SQ}$ could be fitted into three peaks assigned at C-O (286.70 eV), C-C and C-H (285.00 eV) and C-Si (284.33 eV). Conversely, the C1s peak C-Si bonds [50], which is the only C-containing bonds in the PDMS used. Therefore, XPS survey of Si and $\mathrm{C}$ areas both supported the formation of a PDMS-rich surface region in $\mathrm{BC}_{6} \mathrm{SQ} / \mathrm{PDMS}$. 

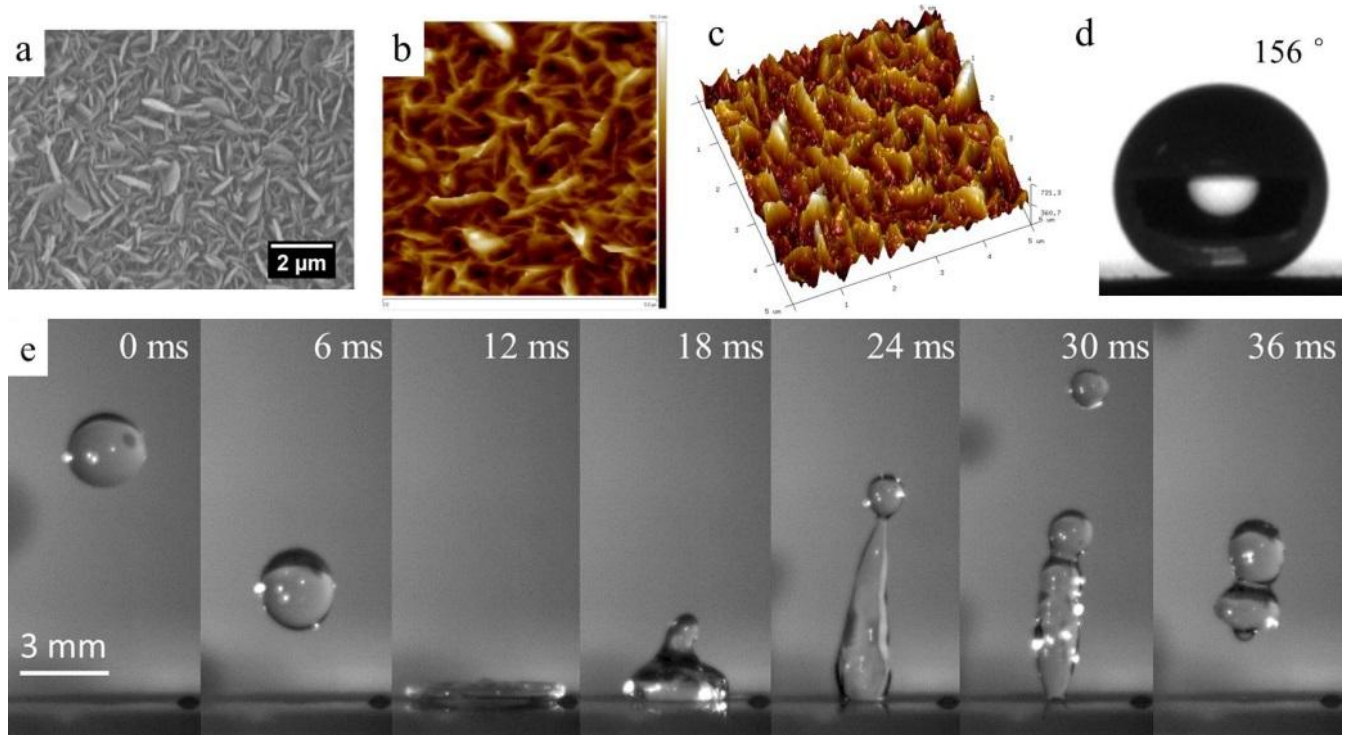

Figure 6. (a) SEM micrographs of the surface of $\mathrm{BC}_{6} \mathrm{SQ} / \mathrm{PDMS}$ coating obtained by visible

light induced polymerization $\left(0.5 \mathrm{~mW} \mathrm{~cm}{ }^{-2}, 30 \mathrm{~min}\right.$ irradiation). Inset: shape of water droplet on $\mathrm{BC}_{6} \mathrm{PSQ} / \mathrm{PDMS}$ coating surface); (b) AFM height image $(5 \mu \mathrm{m} \times 5 \mu \mathrm{m})$; (c) AFM 3D topography of $\mathrm{BC}_{6} \mathrm{PSQ} / \mathrm{PDMS}$ coating surface; (d) High-speed images sequence of a water droplet hitting the $\mathrm{BC}_{6} \mathrm{PSQ} / \mathrm{PDMS}$ coating at an impact velocity of $1.2 \mathrm{~m} \cdot \mathrm{s}^{-1} \pm 0.1 \mathrm{~m} \cdot \mathrm{s}^{-1}$ (falling height of $5 \mathrm{~cm}$ ).

In addition, SEM observation (Figure 6a) revealed that microcrystals of $\mathrm{BC}_{6} \mathrm{SQ} / \mathrm{PDMS}$ still formed a homogeneous array of flat plates exhibiting sharp edges, giving the microstructure a shape similar to sand rose rocks. AFM characterization (Figure 6b-c) confirmed such morphology presenting a high roughness (arithmetic average roughness $R_{a}=$ $98 \pm 10 \mathrm{~nm}$ ). The crystals were shaped like petals or flat plates, growing up to around $1 \mu \mathrm{m}$.

Remarkably, this surface showed high superhydrophobicity. The repellency was such that it was extremely difficult to measure an equilibrium contact angle or a contact angle hysteresis, the water droplets just rolling off the surface. While scanning the surface with the water 
droplet, it was possible however to find some anchoring points corresponding to local heterogeneities in the coating. In this case, the water droplet contact angle was $156^{\circ}$ (Figure 6d). Additionally, the CA hysteresis was found to be zero, as expected from a surface on which water droplets could not adhere. The bouncing drop technique was used to further characterize the resistance of the surface texture to wetting. The bouncing of water droplets on $\mathrm{BC}_{6} \mathrm{SQ} / \mathrm{PDMS}$ surface was observed using a high speed video camera, with increasing falling heights. It was not possible even for the highest falling height (just before fragmentation of the droplet) to produce the forced wetting of the surface texture, the droplet still detaching from the substrate after the first impact, and bouncing on the surface (see Figure 6e). Such a water repellency and pressure resistant superhydrophobic surface is remarkable and might be particularly relevant for underwater applications.

In order to evaluate the environmental stability and solvent resistance properties of this superhydrophobic surface, the influence of exposure to organic solvents, hot water and aqueous solutions displaying a range of $\mathrm{pH}$ was examined (Figure 7). Remarkably, the superhydrophobicity of $\mathrm{BC}_{6} \mathrm{PSQ} / \mathrm{PDMS}$ coating was preserved after immersion during 30 min in different solvents: ethanol, acetone, toluene, chloroform, octane or boiling water (Figure 7a). In all instances, for droplets adhering locally on some defects, the CAs were still extremely high $\left(>150^{\circ}\right)$, and no contact angle hysteresis could be measured $\left(\Delta \theta=0^{\circ}\right)$. Even after being exposed to air for 3 months, the surface retained its water-repellent property. Furthermore, the superhydrophobicity of $\mathrm{BC}_{6} \mathrm{PSQ} / \mathrm{PDMS}$ coating was maintained even after $24 \mathrm{~h}$ immersion in acid/alkali solution with $\mathrm{pH}$ from 1 to 13 (Figure 7b). 

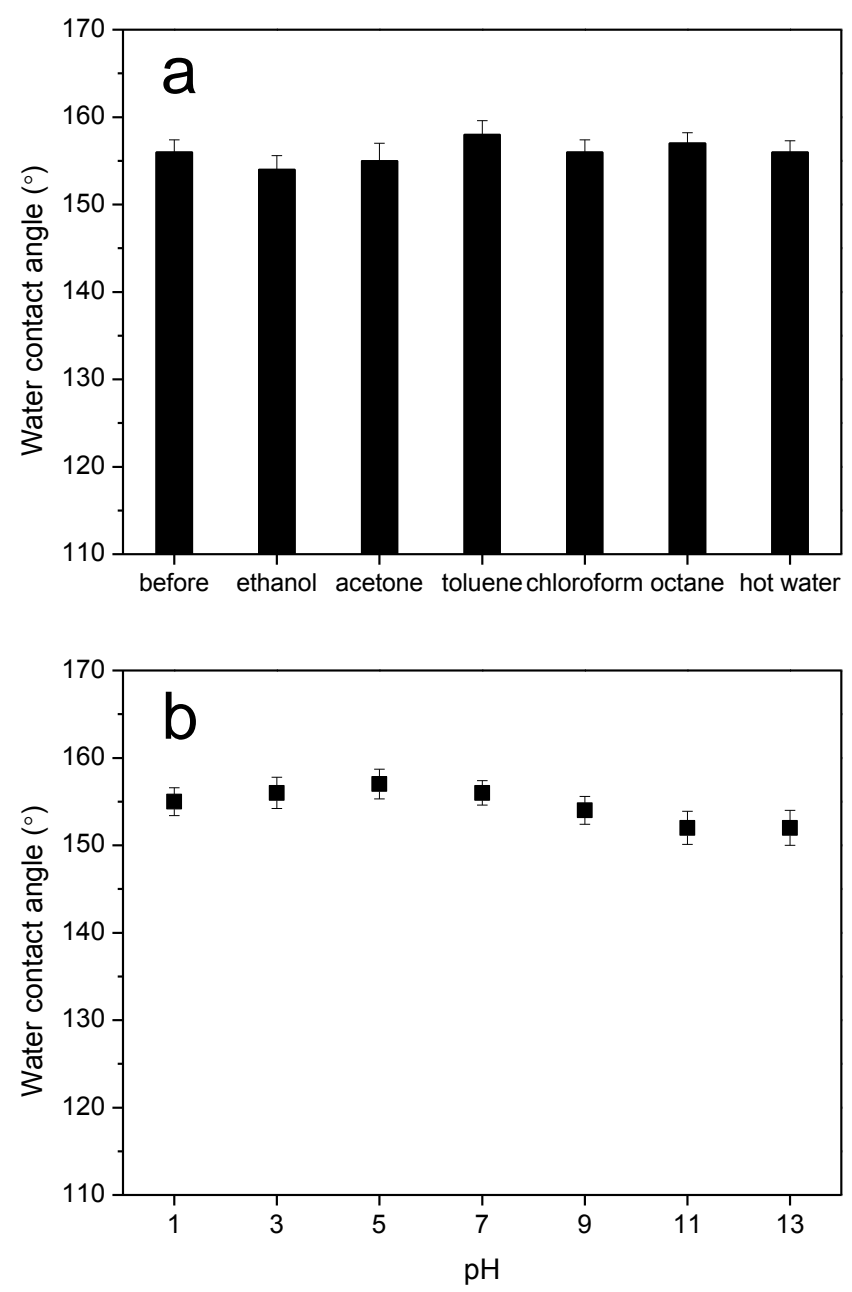

313 Figure 7. (a) The solvent-resistance of the $\mathrm{BC}_{6} \mathrm{PSQ} / \mathrm{PDMS}$ superhydrophobic coating upon treatment with various solvents during $30 \mathrm{~min}$; (b) Variation of water $\mathrm{CA}$ for $\mathrm{BC}_{6} \mathrm{PSQ} / \mathrm{PDMS}$ superhydrophobic coating after immersion in aqueous solutions with different $\mathrm{pH}$ values for $24 \mathrm{~h}$.

The mechanical durability of the $\mathrm{BC}_{6} \mathrm{PSQ} / \mathrm{PDMS}$ superhydrophobic coating was also assessed using an abrasion wear test [51]. The methodology of the abrasion test involved rubbing the $\mathrm{BC}_{6} \mathrm{PSQ} / \mathrm{PDMS}$ coating surface against a rotating abrader wheel (see characterization section for details). The variations of the water CA and sliding angle (SA) values along with abrasion cycles are shown in Figure 8. Interestingly, the surface of $\mathrm{BC}_{6} \mathrm{PSQ} / \mathrm{PDMS}$ coating maintained superhydrophobicity $\left(\geq 150^{\circ}\right)$ even after 20 abrasion 
cycles. Although the SA values increased with the number of abrasion cycles, it is only $14^{\circ}$ after 20 cycles of abrasions. Such results indicated the mechanical stability of the hybrid coating surface.

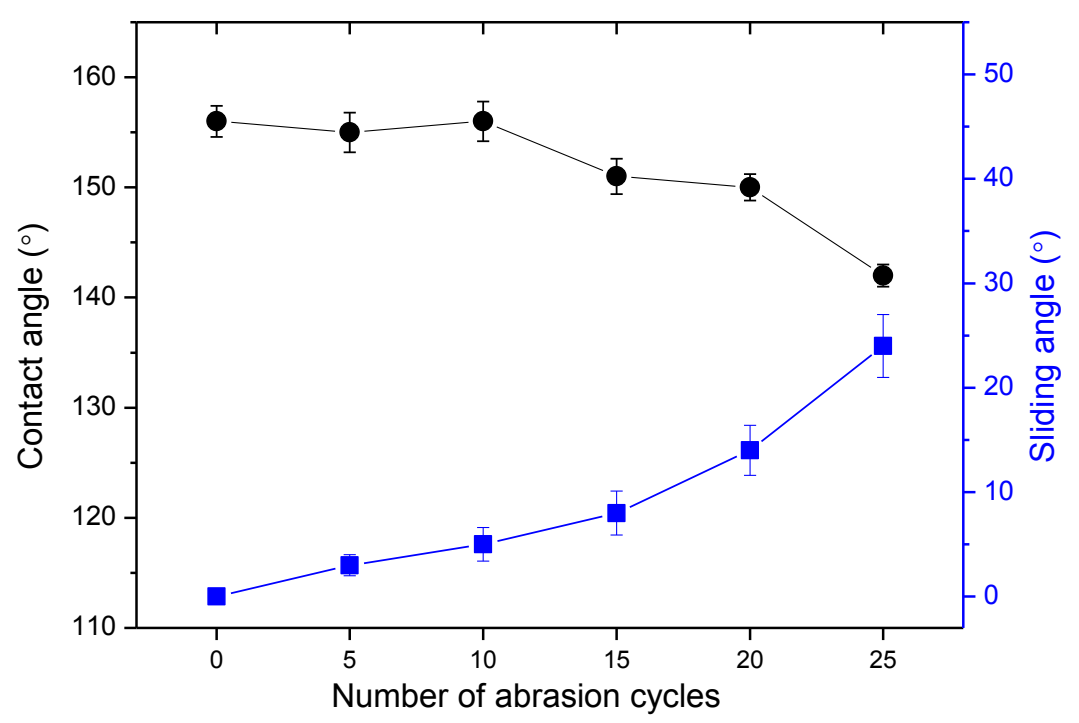

Figure 8. Water $\mathrm{CA}$ and sliding angle of the $\mathrm{BC}_{6} \mathrm{PSQ} / \mathrm{PDMS}$ superhydrophobic coating surface as a function of abrasion cycles with a pressure of $\sim 2.4 \mathrm{kPa}$.

Such coating robustness was attributed to siloxane cross-linked structure as well as the high modulus value provided by the crystalline structure. In agreement with these two hypotheses, ${ }^{29} \mathrm{Si}$ solid state NMR spectroscopy (Figure S4) revealed a relatively high degree of condensation $(72 \%)$. Additionally, the Derjaguin-Müller-Toporov (DMT) fit model was used to estimate the elastic modulus using the unloading parts of the AFM force curves. The average values of the DMT elastic modulus of $\mathrm{BC}_{6} \mathrm{SQ} / \mathrm{PDMS}$ surface was $3.2 \pm 1.2 \mathrm{GPa}$

\section{(Figure 9).}



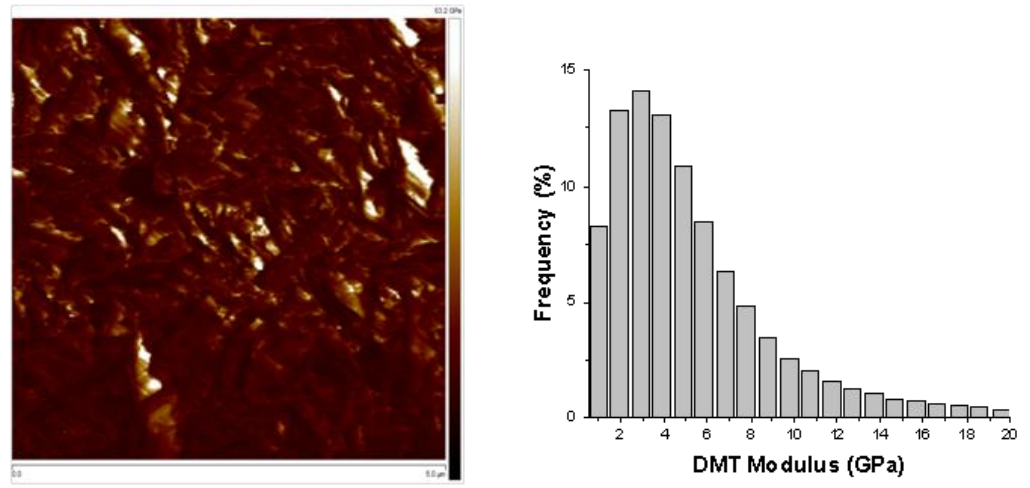

Figure 9. Representative maps DMT modulus and corresponding histogram of the

$\mathrm{BC}_{6} \mathrm{SQ} / \mathrm{PDMS}$ sample obtained with PeakForce QNM.

\section{Conclusion}

We have demonstrated a new strategy based on light-induced crystallization to fabrication of hybrid superhydrophobic coatings for the first time. Of particular interest is that the described light-induced crystallization process proceeds in bulk without any solvent and water, thus obviating not only the insolubility problem of precursors but also the environmental issue. The one-step sol-gel polymerization of bridged precursor $\mathrm{BC}_{6} \mathrm{TMS}$ is catalyzed by in situ light irradiation generated photoacid of $n$-propane sulfonic acid that formed polysilsesquioxane hybrid coating shows micro/nanoscale hierarchical structure. Template-free organosilane self-assembly accounts for formation of crystalline nanolayers assembling in flat plates microcrystals. With sufficient roughness simply tuned by irradiation intensity, the micro/nanotextured surfaces result in high water contact angles $\left(\geq 156^{\circ}\right)$ and no contact angle hysteresis could be measured $\left(\Delta \theta=0^{\circ}\right)$. Furthermore, the cross-linked silsesquioxane hybrid coatings are mechanically robust (20 cycles abrasion and with a DMT elastic modulus value of $3.2 \pm 1.2 \mathrm{GPa}$ ) as well as chemically (various organic solvents, acid/alkali solution) and thermally resistant (even for boiling water). Thus, the present strategy has potential applications for superhydrophobic coatings, in particular for large-area, temperature or even UV light sensitive substrates. 
Supporting Information. ${ }^{29} \mathrm{Si}$ solid state SPE-MAS NMR spectra of the visible LED cured $\mathrm{BC}_{6} \mathrm{SQ}$ hybrid coatings (Figure S1), polarized optical microscopy images of the $\mathrm{BC}_{\mathrm{n}} \mathrm{SQ}$ hybrid coatings (Figure S2), XRD patterns of the visible LED cured hybrid coatings (Figure S3), ${ }^{29} \mathrm{Si}$ solid state SPE-MAS NMR spectrum of the visible LED cured $\mathrm{BC}_{6} \mathrm{SQ} / \mathrm{PDMS}$ hybrid coatings (Figure S4).

\section{Acknowledgements}

The authors would like to thank the financial support from the National Natural Science Foundation of China (No. 51503072), Natural Science Foundation of Jiangsu Province (No. BK20150419) and Six Talent Peaks Project in Jiangsu Province (No. 2016XCL010, 2017KTHY007).

\section{References}

[1] C. Peng, Z. Chen, M.K. Tiwari, All-organic superhydrophobic coatings with mechanochemical robustness and liquid impalement resistance, Nat. Mater. 17 (2018) $355-360$.

[2] B. Su, Y. Tian, L. Jiang, Bioinspired Interfaces with Superwettability: From Materials to Chemistry, J. Am. Chem. Soc. 138 (2016) 1727-1748.

[3] S. Wang, K. Liu, X. Yao, L. Jiang, Bioinspired Surfaces with Superwettability: New Insight on Theory, Design, and Applications, Chem. Rev. 115 (2015) 8230-8293.

[4] B. Bhushan, Y.C. Jung, Natural and biomimetic artificial surfaces for superhydrophobicity, self-cleaning, low adhesion, and drag reduction, Prog. Mater. Sci. 56 (2011) 1-108. 
381

382

383

384

385

386

387

[5] R. Blossey, Self-cleaning surfaces — virtual realities, Nat. Mater., 2 (2003) 301.

[6] Y. Lu, S. Sathasivam, J. Song, C.R. Crick, C.J. Carmalt, I.P. Parkin, Robust self-cleaning surfaces that function when exposed to either air or oil, Science 347 (2015) 1132-1135.

[7] K.M. Wisdom, J.A. Watson, X. Qu, F. Liu, G.S. Watson, C.H. Chen, Self-cleaning of superhydrophobic surfaces by self-propelled jumping condensate, Proc. Natl Acad. Sci. 110 (2013) 7992-7997.

[8] F. Zhang, L. Zhao, H. Chen, S. Xu, D.G. Evans, X. Duan, Corrosion Resistance of Superhydrophobic Layered Double Hydroxide Films on Aluminum, Angew. Chem. Int. Ed. 47 (2008) 2466-2469.

[9] P.M. Barkhudarov, P.B. Shah, E.B. Watkins, D.A. Doshi, C.J. Brinker, J. Majewski, Corrosion inhibition using superhydrophobic films, Corros. Sci. 50 (2008) 897-902.

[10] K. Liu, M. Zhang, J. Zhai, J. Wang, L. Jiang, Bioinspired construction of Mg-Li alloys surfaces with stable superhydrophobicity and improved corrosion resistance, Appl. Phys. Lett. $92(2008) 183103$.

[11] X. Zhou, J. Kong, J. Sun, H. Li, C. He, Stable Superhydrophobic Porous Coatings from Hybrid ABC Triblock Copolymers and Their Anticorrosive Performance, ACS Appl. Mater. Interfaces 9 (2017) 30056-30063.

[12] J. Ou, B. Perot, J.P. Rothstein, Laminar drag reduction in microchannels using ultrahydrophobic surfaces, Phys. Fluids 16 (2004) 4635-4643.

[13] S.T. Yohe, Y.L. Colson, M.W. Grinstaff, Superhydrophobic Materials for Tunable Drug Release: Using Displacement of Air To Control Delivery Rates, J. Am. Chem. Soc. 134 (2012) 2016-2019. 
403

404

405

406

407

408

409

410

411

412

413

414

415

416

417

418

419

420

421

422

423

424

[14] P. Ball, Engineering Shark skin and other solutions, Nature 400 (1999) 507-509.

[15] F. Mumm, A.T.J. van Helvoort, P. Sikorski, Easy Route to Superhydrophobic Copper-Based Wire-Guided Droplet Microfluidic Systems, ACS Nano 3 (2009) 2647-2652.

[16] L. Jiang, R. Wang, B. Yang, T.J. Li, D.A. Tryk, A. Fujishima, K. Hashimoto, D.B. Zhu, Binary cooperative complementary nanoscale interfacial materials, Pure Appl. Chem. 72 (2000) 83-90.

[17] L. Feng, S. Li, Y. Li, H. Li, L. Zhang, J. Zhai, Y. Song, B. Liu, L. Jiang, D. Zhu, Super-Hydrophobic Surfaces: From Natural to Artificial, Adv. Mater. 14 (2002) 1857-1860.

[18] W. Barthlott, C. Neinhuis, Purity of the sacred lotus, or escape from contamination in biological surfaces, Planta 202 (1997) 1-8.

[19] G. Azimi, R. Dhiman, H.M. Kwon, A.T. Paxson, K.K. Varanasi, Hydrophobicity of rare-earth oxide ceramics, Nat. Mater. 12 (2013) 315.

[20] Y. Liu, L. Moevius, X. Xu, T. Qian, J.M. Yeomans, Z. Wang, Pancake bouncing on superhydrophobic surfaces, Nat. Phys. 10 (2014) 515.

[21] H.Y. Erbil, A.L. Demirel, Y. Avci, O. Mert, Transformation of a Simple Plastic into a Superhydrophobic Surface, Science 299 (2003) 1377-1380.

[22] J.T. Han, Xu, K. Cho, Diverse Access to Artificial Superhydrophobic Surfaces Using Block Copolymers, Langmuir 21 (2005) 6662-6665.

[23] Z. Sun, B. Liu, S. Huang, J. Wu, Q. Zhang, Facile fabrication of superhydrophobic coating based on polysiloxane emulsion, Prog. Org. Coat. 102 (2017) 131-137.

[24] F. Shi, Z. Wang, X. Zhang, Combining a Layer-by-Layer Assembling Technique with Electrochemical Deposition of Gold Aggregates to Mimic the Legs of Water Striders, Adv. 
Mater. 17 (2005) 1005-1009.

[25] T. Sun, G. Wang, H. Liu, L. Feng, L. Jiang, D. Zhu, Control over the Wettability of an Aligned Carbon Nanotube Film, J. Am. Chem. Soc. 125 (2003) 14996-14997.

[26] Q. Ke, G. Li, Y. Liu, T. He, X.-M. Li, Formation of Superhydrophobic Polymerized n-Octadecylsiloxane Nanosheets, Langmuir 26 (2009) 3579-3584.

[27] J.T. Han, D.H. Lee, C.Y. Ryu, K. Cho, Fabrication of Superhydrophobic Surface from a Supramolecular Organosilane with Quadruple Hydrogen Bonding, J. Am. Chem. Soc. 126 (2004) 4796-4797.

[28] J. Genzer, K. Efimenko, Creating Long-Lived Superhydrophobic Polymer Surfaces Through Mechanically Assembled Monolayers, Science 290 (2000) 2130-2133.

[29] L. Li, G. Zhang, Z. Su, One-Step Assembly of Phytic Acid Metal Complexes for Superhydrophilic Coatings, Angew. Chem. 128 (2016) 9239-9242.

[30] R. Taurino, E. Fabbri, M. Messori, F. Pilati, D. Pospiech, A. Synytska, Facile preparation of superhydrophobic coatings by sol-gel processes, J. Colloid Interf. Sci. 325 (2008) 149-156. [31] M. A. Aegerter, R. Almeida, A. Soutar, K. Tadanaga, H. Yang, and T. Watanabe, Coatings made by sol-gel and chemical nanotechnology. J. Sol-Gel Sci. Technol. 47 (2008) 203-236.

[32] J. Li, Z. Zhao, Y. Zhang, B. Xiang, X. Tang, and H. She, Facile fabrication of superhydrophobic silica coatings with excellent corrosion resistance and liquid marbles. J. Sol-Gel Sci. Technol. 80 (2016) 208-214.

[33] D. Lin, X. Zeng, H. Li, X. Lai, T. Wu, One-pot fabrication of superhydrophobic and flame-retardant coatings on cotton fabrics via sol-gel reaction, J. Sol-Gel Sci. Technol. 533 (2019) 198-206. 
[34] T.M. Schutzius, I.S. Bayer, G.M. Jursich, A. Das, C.M. Megaridis, Superhydrophobicsuperhydrophilic binary micropatterns by localized thermal treatment of polyhedral oligomeric silsesquioxane (POSS)-silica films, Nanoscale 4 (2012) 5378-5385.

[35] Y. Jin, P. Wang, K. Hou, Y. Lin, L. Li, S. Xu, J. Cheng, X. Wen, P. Pi, Superhydrophobic porous surface fabricated via phase separation between polyhedral oligomeric silsesquioxanebased block copolymer and polyethylene glycol, Thin Solid Films 649 (2018) 210-218.

[36] A. Javadi, H.S. Mehr, M. Sobani, M.D. Soucek, Cure-on-command technology: A review of the current state of the art, Prog. Org. Coat. 100 (2016) 2-31.

[37] B.J. Sparks, E.T. Hoff, L. Xiong, J.T. Goetz, D.L. Patton, Superhydrophobic Hybrid Inorganic-Organic Thiol-ene Surfaces Fabricated via Spray-Deposition and Photopolymerization, ACS Appl. Mater. Interfaces 5 (2013) 1811-1817.

[38] S. Qiang, K. Chen, Y. Yin, C. Wang, Robust UV-cured superhydrophobic cotton fabric surfaces with self-healing ability, Mater. Design 116 (2017) 395-402.

[39] S. Kato, A. Sato, Micro/nanotextured polymer coatings fabricated by UV curing-induced phase separation: creation of superhydrophobic surfaces, J. Mater. Chem. 22 (2012) 8613-8621.

[40] Y. Liu, Q. Wang, X. Zhu, F. Yang, M.Y. Akram, J. Nie, Preparation of superhydrophobic surface via one-step photopolymerization, Mater. Lett. 190 (2017) 48-51.

[41] C. Dietlin, S. Schweizer, P. Xiao, J. Zhang, F. Morlet-Savary, B. Graff, J.P. Fouassier, J. Lalevee, Photopolymerization upon LEDs: new photoinitiating systems and strategies, Polym. Chem. 6 (2015) 3895-3912.

[42] A. Chemtob, L. Ni, C. Croutxé-Barghorn, A. Demarest, J. Brendlé, L. Vidal, S. Rigolet, 
Self-Organized Poly(n-octadecylsilsesquioxane) Films via Sol-Gel Photopolymerization, Langmuir 27 (2011) 12621-12629.

[43] L. Ni, M. Wu, F. Chen, I. Deroche, A. Chemtob, Ordering minimalist bridged polysilsesquioxane films under visible LED light irradiation, Soft Mater. 15 (2017) 196-204.

[44] H.W. Oviatt, K.J. Shea, J.H. Small, Alkylene-bridged silsesquioxane sol-gel synthesis and xerogel characterization. Molecular requirements for porosity, Chem. Mater. 5 (1993) 943-950.

[45] J.E. Sader, J.W.M. Chon, P. Mulvaney, Calibration of rectangular atomic force microscope cantilevers, Rev. Sci. Instrum. 70 (1999) 3967-3969.

[46] J.L. Bantignies, L. Vellutini, D. Maurin, P. Hermet, P. Dieudonne, M. Wong Chi Man, J.R. Bartlett, C. Bied, J.L. Sauvajol, J.J.E. Moreau, Insights into the Self-Directed Structuring of Hybrid Organic-Inorganic Silicas through Infrared Studies, J. Phys. Chem. B 110 (2006) 15797-15802.

[47] L. Ni, A. Chemtob, C. Croutxé-Barghorn, J. Brendlé, L. Vidal, S. Rigolet, Kinetics, Thermodynamics, and Dynamics in Organosilane Self-Assembly, J. Phys. Chem. C 116 (2012) 24320-24330.

[48] L. Gránásy, T. Pusztai, T. Börzsönyi, J.A. Warren, J.F. Douglas, A general mechanism of polycrystalline growth, Nat. Mater. 3 (2004) 645.

[49] M.R. Alexander, R.D. Short, F.R. Jones, W. Michaeli, C.J. Blomfield, A study of $\mathrm{HMDSO} / \mathrm{O}_{2}$ plasma deposits using a high-sensitivity and -energy resolution XPS instrument: curve fitting of the Si 2p core level, Appl. Surf. Sci. 137 (1999) 179-183.

[50] G.Beamson, D.Briggs, High Resolution XPS of Organic polymers. The Scienta ESCA 
491 300, Database., John Wiley \& Sons. 1992.

492 [51] A. Milionis, E. Lotha, I.S. Bayer, Recent advances in the mechanical durability of 493 superhydrophobic materials, Adv. Colloid Interface. 229 (2016) 57-79. 
${ }^{\dagger}$ Key Laboratory for Palygorskite Science and Applied Technology of Jiangsu Province,

ॠ Université de Haute-Alsace, CNRS, IS2M UMR7361, F-68100 Mulhouse, France

${ }^{\S}$ Université de Strasbourg, France

505

506

*Corresponding authors:

Dr. Lingli Ni; E-mail: linglini@hyit.edu.cn; Tel: +86 5178355 9056; Fax: +86 5178355 9056; 9056 


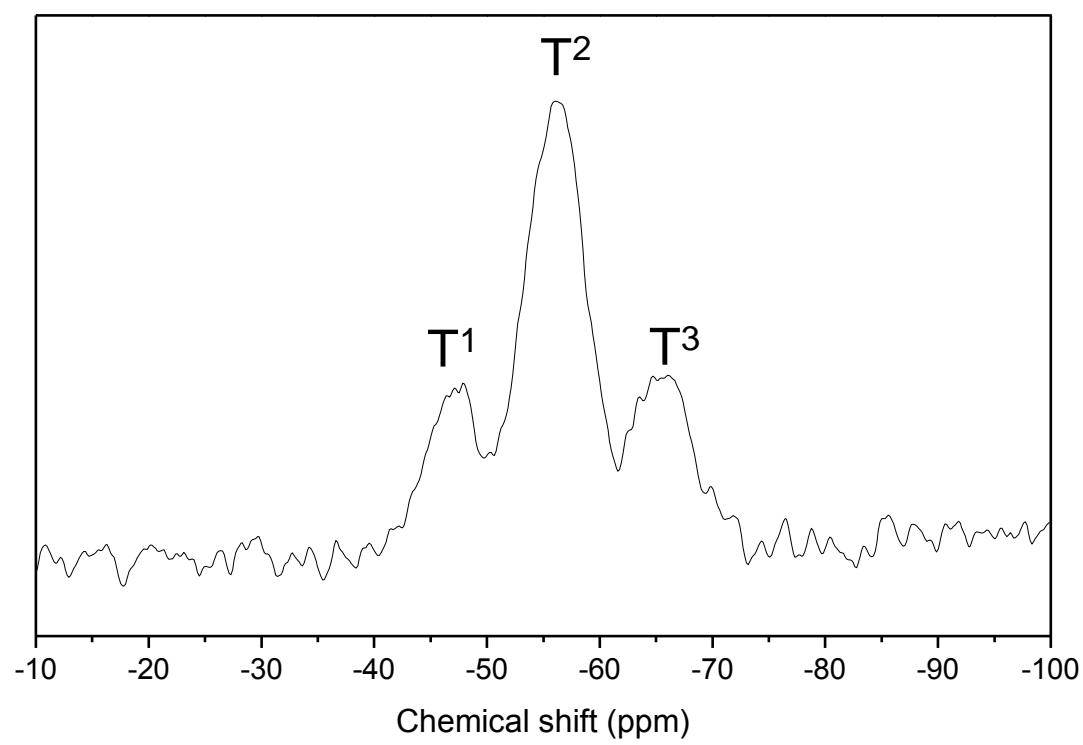

516

517 Figure S1. ${ }^{29}$ Si solid state SPE-MAS NMR spectra of the visible LED cured $\mathrm{BC}_{6}$ SQ hybrid

518 coatings derived from $\mathrm{BC}_{6} \mathrm{TMS}$ precursor $\left(\mathrm{I}=0.5 \mathrm{~mW} / \mathrm{cm}^{2}, \mathrm{RH}=50 \%, \mathrm{~T}=25^{\circ} \mathrm{C}\right)$.

519

520 

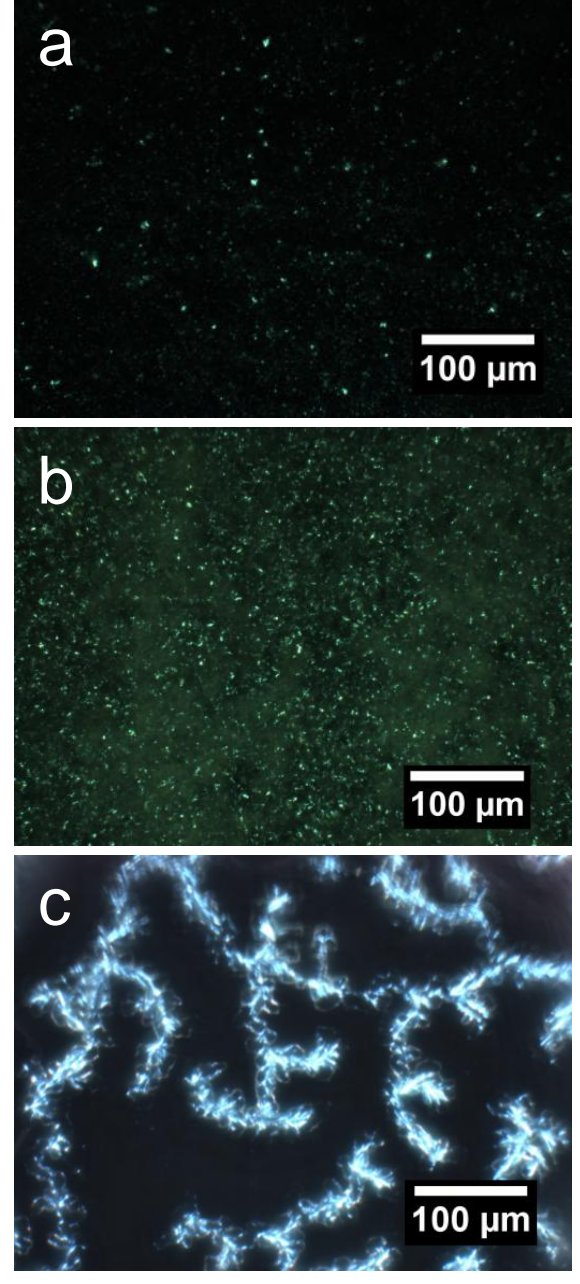

522 Figure $\mathrm{S2}$. POM micrographs of the $\mathrm{BC}_{\mathrm{n}} \mathrm{SQ}$ hybrid coatings: (a) $\mathrm{BC}_{10} \mathrm{SQ}$, (b) $\mathrm{BC}_{6} \mathrm{SQ}$, and (c)

$523 \quad \mathrm{BC}_{2} \mathrm{SQ}\left(\mathrm{I}=0.5 \mathrm{~mW} / \mathrm{cm}^{2}, \mathrm{RH}=50 \%, \mathrm{~T}=25^{\circ} \mathrm{C}\right)$. 


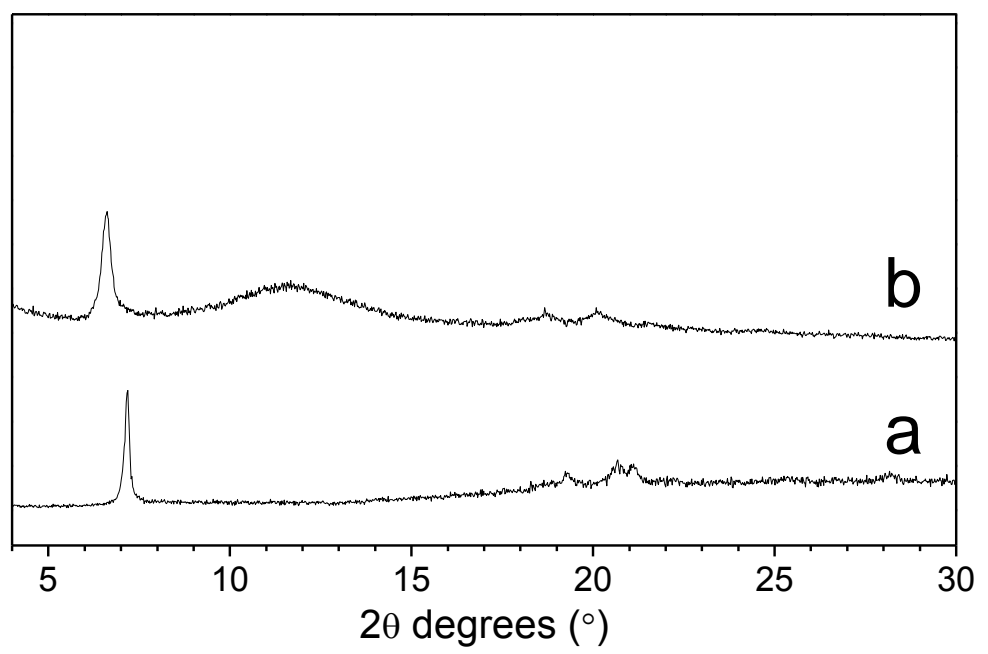

525

Figure S3. XRD patterns of the visible LED cured hybrid coatings: (a) $\mathrm{BC}_{6} \mathrm{SQ}$; (b)

$527 \quad \mathrm{BC}_{6} \mathrm{SQ} / \mathrm{PDMS}\left(\mathrm{I}=0.5 \mathrm{~mW} / \mathrm{cm}^{2}, \mathrm{RH}=50 \%, \mathrm{~T}=25^{\circ} \mathrm{C}\right)$.

528 


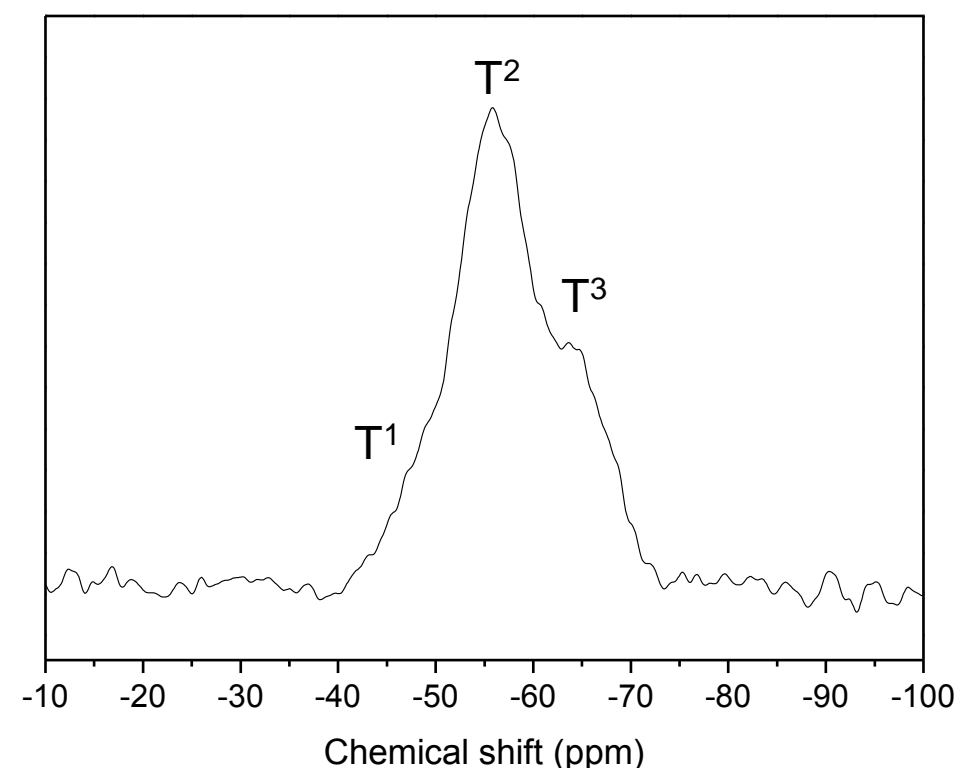

529

Chemical shift (ppm)

530 Figure S4. ${ }^{29} \mathrm{Si}$ solid state SPE-MAS NMR spectrum of the visible LED cured $\mathrm{BC}_{6} \mathrm{SQ} / \mathrm{PDMS}$

531 hybrid coatings $\left(\mathrm{I}=0.5 \mathrm{~mW} / \mathrm{cm}^{2}, \mathrm{RH}=50 \%, \mathrm{~T}=25^{\circ} \mathrm{C}\right)$.

532

533

534 